\title{
Experimental Investigation on the Feasibility of Using a Fresnel Lens as a Solar-Energy Collection System for Enhancing On-Orbit Power Generation Performance
}

\author{
Tae-Yong Park, ${ }^{1}$ Joo-Yong Jung, ${ }^{2}$ and Hyun-Ung $\mathrm{Oh}^{1}$ \\ ${ }^{1}$ Space Technology Synthesis Laboratory, Department of Aerospace Engineering, Chosun University, \\ 375 Seosuk-dong, Dong-gu, Gwangju 501-759, Republic of Korea \\ ${ }^{2}$ Spaceborne SAR R\&D Lab, LIG Nex1, Yongin, Republic of Korea \\ Correspondence should be addressed to Hyun-Ung Oh; ohu129@chosun.ac.kr
}

Received 21 October 2016; Revised 11 January 2017; Accepted 26 January 2017; Published 20 February 2017

Academic Editor: Christopher J. Damaren

Copyright @ 2017 Tae-Yong Park et al. This is an open access article distributed under the Creative Commons Attribution License, which permits unrestricted use, distribution, and reproduction in any medium, provided the original work is properly cited.

\begin{abstract}
Cube satellites have a limitation for generating power because of their cubic structure and extremely small size. In addition, the incidence angle between the sun and the solar panels continuously varies owing to the revolution and rotation of the satellite according to the attitude control strategy. This angle is an important parameter for determining the power generation performance of the cube satellite. In this study, we performed an experimental feasibility study that uses a Fresnel lens as a solar-energy collection system for cube satellite applications, so that the power generation efficiency can be enhanced under the worst incidence angle condition between the sun and solar panels by concentrating and redirecting solar energy onto the solar panels with a commercial Fresnel lens. To verify the effectiveness of the proposed system, we conducted a power-measurement test using a solar simulator and Fresnel lenses at various angles to the light source. In addition, we predicted the on-orbit power-generation enhancement achieved by employing the solar-energy collection system with various attitude control strategies.
\end{abstract}

\section{Introduction}

A cube satellite is a parametric design specification for a picoclass satellite that is based on a volume of $1000 \mathrm{~cm}^{3}$ and a required mass of $1.33 \mathrm{~kg}$ or less, as a standard size of $1 \mathrm{U}$ (unit). Its low construction cost and short development period make it a cost-effective platform for various missions in space [1]. Universities around the world are actively participating in cube satellite development programs for academic and training purposes. These programs offer participants unique opportunities providing hands-on experience [2,3]. Because of these advantages and the increasing adoption in the fields of scientific investigation, military, and technology demonstration, cube satellites are also attracting attention from industries and space-research organizations across the world [4-6].

Recent advances in microelectronics and component manufacturing technology for space applications have led to the miniaturization and reduction of payloads and cube satellite parts; thus, the mission capability of cube satellites has been continuously enhanced [7]. However, the missions of cube satellites are more challenging than those of regular satellites, and the overall required power of cube satellites also tends to be higher. Most satellites, including cube satellites, use photovoltaic solar cells, which are a wellknown and reliable source of power. Therefore, a sufficient surface area for the solar cells is a very important system design parameter for satellites. However, cube satellites are considerably smaller than typical satellites; thus, it is far more difficult to provide a sufficiently large area for the installation of the solar cells. Additionally, the available area for solar cells must typically be shared with other appendages, such as the payload, communication antenna, camera, and access port. The number of panels that can be simultaneously oriented toward the sun is limited owing to the cube-shaped configuration. The variation in the incidence 
angles of sunlight with respect to the solar panels is also an important parameter for determining the power generation performance of satellites because this angle varies continuously according to the attitude control strategy and the revolution of the satellite. These are the main restrictions on the power generation performance of cube satellites. To overcome these performance limitations, cube satellite developers implement additional deployable solar panels to increase the power generation performance. Recently, many cube satellite vendors have produced deployable solar panels [8-10], most of which are based on passive deployment mechanisms using hinges and torsional springs. However, these deployable panels require an additional launch-locking mechanism to securely hold and safely release them during launch and on-orbit phases. The deployed solar panels can offer greatly improved power generation but require an increased system complexity and pose the risk of deployment failure, which might seriously affect the mission. In addition, while a deployable solar panel faces the sun and actively generates power, the power generation of the solar panels integrated on the satellite is limited because of the shadow effect induced by an existence of the on-board deployable panel.

To enhance the power generation capability of cube satellite, we focused on CPV (Concentrating PhotoVoltaic) systems, which are widely used for ground-system applications [11-19]. The CPV system for ground applications improves the power generation efficiency of solar cells by concentrating solar-energy onto a relatively small area of the solar cells by using optical systems such as lenses or curved-mirrors. A great benefit of the CPV system is its costeffectiveness, which is achieved through the reduction of the solar cell area compared to the alternatives that reduce the solar cell area with standard non-CPV modules.

High-concentrating photovoltaic (HCPV) systems [1113] use concentrating optics, such as dish reflectors or Fresnel lenses to focus sunlight with a concentration ratio ranging from 300 to over 1,000 suns and typically employ multijunction solar cells, which have a high efficiency and lower efficiency loss associated with increases in temperature or life degradation as compared to conventional Si solar cells. Rumyantsev et al. [13] proposed an HCPV module that can enhance the overall power generation efficiency by using a primary Fresnel lens to perform the main concentration and a convex lens as a secondary optical element to ensure uniform illumination and to reduce the accuracy requirements for alignment and tracking. Low-concentration photovoltaic (LCPV) systems [14-16] are less complex than HCPV systems and are widely used in ground-based system applications owing to their higher tracking tolerances, passive heat sinks, and lower construction costs. Uematsu et al. [16] proposed and developed a flat-plate static LCPV system, which can reduce the cost of photovoltaic modules and has a larger tolerance for the acceptance angle than the HCPV system. The flat-plate static LCPV module consists of a cover glass, solar cells, and a reflector sheet with submillimeter $\mathrm{V}$-grooves. The solar energy reflected from the $\mathrm{V}$-grooved reflector sheet is completely reflected at the cover-glass surface and illuminated on the solar cells. Thus, the system concentrates solar energy at a concentration ratio ranging from 1.5 to 2 suns.

Luminescent solar concentrators (LSC) [17-19] are an emerging type of solar concentration technology and are still in the research stage. A sheet of transparent material doped with fluorophores contains luminescent particles that absorb a fraction of the incident solar spectrum. The absorbed solar energy is directed to the edges of the sheet by total internal reflection and collected by the solar cells attached there. Thus, the LSC provides a high concentration ratio without a solartracker or an additional cooling system. Wang et al. [19] proposed an LSC with a silicon solar cell module that can provide a higher power generation efficiency than one using an organic dye with self-absorption by employing a rare-earth complex that can achieve zero self-absorption.

However, the CPV technologies have seen only limited consideration for cube satellite applications. To date, research into CPV systems for space applications has been mostly considered for deployable systems [20-22] or space-based solar power (SSP) systems [23, 24]. Habraken et al. [22] investigated the effectiveness of using CPV technologies for spacecraft with high power requirements. Two concepts of CPV technologies based on reflective and refractive concentrating elements were compared to conventional solar arrays in various aspects including environmental aging effects of optical systems, off-pointing sensitivity, and thermal management of the solar array. Mori et al. [24] investigated the SSP systems, which collect solar energy using an extralarge optical lenses or mirror systems in-orbit and transfer the power to an on-ground facility via microwaves or lasers.

Despite the great advantages of CPV systems regarding their power generation performance, applying the groundbased CPV systems to space missions leads to technical risks and increases the system complexity. Most current CPV technologies for ground-based systems require a relatively large optical system to efficiently focus the incident solar energy onto the solar cells. In addition, they require a solar tracking system to secure the acceptance angle of the CPV module with respect to the sun vector and an additional cooling system to avoid the power generation efficiency loss of the solar cell due to the increase in temperature caused by the solar-energy concentration. Therefore, the existing ground-based CPV technologies are impractical for space applications without design modification, especially for cube satellites, which have an extremely limited accommodation area.

To overcome the limitations of conventional groundbased CPV technologies, Oh and Park [25] proposed a CPV system for cube satellite applications. This system has the potential to increase the power generation efficiency using a commercial multiarray lens system installed on the edge of the solar panels even under the worst incidence angle conditions between the sun and the solar panels. The feasibility of the CPV system was verified through a power-measurement test using a solar simulator and a CPV system with a commercial multiarray lens system. However, in this study, the on-orbit power generation performance of a satellite with a CPV system according to the attitude control strategy was not investigated. 
In this study, we propose a solar-energy collection system for cube satellite applications using a commercial PMMA (polymethyl methacrylate) Fresnel lens system, which provides an enhanced power generation efficiency compared to the multiarray lens system proposed by Oh and Park [25]. The effectiveness of the proposed solar-energy collection system was demonstrated by a power-measurement test using a solar simulator and Fresnel lens system under various incidenceangle conditions with a light source. In addition, we predicted the enhancement of the power generation efficiency of the proposed solar-energy collection system according to the various attitude control profiles of the satellite by an on-orbit power generation simulation using the commercial software STK (Systems Tool Kit) [26]. In the simulations, we confirmed that the proposed solar-energy collection system with the Fresnel lens system installed on the edge of the solar panel at an optimized installation angle is effective for providing a much higher power generation performance for the cube satellite as compared to the conventional configuration using a multiarray lens system [25].

\section{Concept of Solar-Energy Collection Systems for Cube Satellite Applications}

The solar-energy collection system proposed in this study is one of the main payloads of the STEP Cube Lab (Cube Laboratory for Space Technology Experimental Project), which is a $1 \mathrm{U}$ standardized cube satellite developed by STSL (Space Technology Synthesis Laboratory) at Chosun University in Korea. Figure 1 shows the cube satellite configuration of the STEP Cube Lab, whose main mission objective is the on-orbit verification of core space technologies researched in domestic universities that are potential candidates for future space programs. To achieve the mission objectives of the STEP Cube Lab, five technologies were chosen: a microelectromechanical system-based solid propellant thruster, a novel nonexplosive holding and release mechanism triggered by nichrome burn wire heating, a variable-emittance radiator, a phase-change material, and the solar-energy collection system proposed in this study. The STEP Cube Lab mission will be performed in a sun-synchronous orbit at an altitude of $600 \mathrm{~km}$ for a duration of 1 year after the launch and is scheduled for 2017.

In the case of the STEP Cube Lab, the satellite employs a passive attitude-stabilization method [27] using a permanent magnet and hysteresis damper, which has been widely used for cube satellite. This method provides effective attitudestabilization performance for satellites, especially cube satellites with an extremely small accommodation space, as the system has a considerably small mass of $50 \mathrm{~g}$ and does not consume power. A satellite using a permanent magnet aligns with the direction of the local earth magnetic field and performs two cycles of rotation per orbit. Therefore, the attitude control strategy is an important parameter for determining the power generation efficiency of the satellite, as the incidence angle $\beta$ between the sun vector and the satellite varies continuously owing to the revolution and rotation of the satellite.

To overcome the aforementioned limitations of applying ground-based conventional CPV technologies to cube
TABLE 1: Specification of a solar simulator.

\begin{tabular}{lc}
\hline Name & $\begin{array}{c}\text { SolarTrainer Junior (IKS, } \\
\text { Germany) }\end{array}$ \\
\hline Irradiation power source & Halogen lamp \\
Illumination intensity & $150 \mathrm{~W} / \mathrm{m}^{2}$ \\
Solar cell & Polycrystalline Si solar cell \\
Cell efficiency & $17 \%$ \\
Open-circuit voltage $\left(V_{\mathrm{oc}}\right)$ & $0.5 \mathrm{~V}($ single cell) \\
Short-circuit current $\left(I_{\mathrm{sc}}\right)$ & $1.5 \mathrm{~A}\left(\right.$ at $\left.1000 \mathrm{~W} / \mathrm{m}^{2}\right)$ \\
Cell size & $5 \mathrm{~cm} \times 10 \mathrm{~cm}($ single cell, total 4 \\
\hline
\end{tabular}

satellites, we propose a cube satellite with a solar-energy collection system by employing a Fresnel lens system. This system is a photovoltaic power generation system that can enhance the power generation efficiency by using Fresnel lenses. Figure 2 illustrates the basic principle of the proposed solar-energy collection system proposed in this study. The Fresnel lenses installed on the edge of the solar panel collect the solar energy and illuminate it onto the solar panel surface even under the worst condition of the angle $\beta$ between the sun and the solar panel. By installing the Fresnel lenses on the edge of the solar panel at an optimized angle, the light intensity and duration of the light redirected onto the solar panel are increased. In addition, the Fresnel lenses installed on the edge of the solar panel can minimize the performance reduction occurring because of the presence of the lenses according to $\beta$ angle variation, which is suitable for power generation. Thus, the system proposed in this study has the potential to enhance the power generation efficiency, even though the $\beta$ angle between the sun and the solar panel varies continuously according to the attitude control strategy of the satellite. In the STEP mission, the Fresnel lenses are installed on the edge of the solar panels in the $+X$ and $-X$ directions, as shown in Figure 1, to verify the proposed solarenergy collection system by comparing the power generation performance between the solar panel with and without the Fresnel lenses on-orbit.

\section{Power-Measurement Test Set-Up}

To verify the effectiveness of the solar-energy collection system proposed in this study, a power-measurement test was performed using a solar simulator and a commercial Fresnel lens, as shown in Figure 3. Table 1 lists the specifications of the solar simulator (SolarTrainer Junior, IKS (Germany)) used in this study. The simulator consists of a polycrystalline $\mathrm{Si}$ solar cell with a conversion efficiency of $17 \%$, an open-circuit voltage of $0.5 \mathrm{~V}$, and a short-circuit current of $1.5 \mathrm{~A}$. A halogen lamp with an illumination intensity of $150 \mathrm{~W} / \mathrm{m}^{2}$ is used as an irradiation source, and multimeters are used to measure the current and voltage output from the solar cells. The variation in the sun incidence angle with respect to the solar panel due to the rotation and revolution of the satellite was simulated by adjusting the angle of the light source and solar panel of the simulator. The angles $\alpha$ and $\beta$ were defined as shown in 


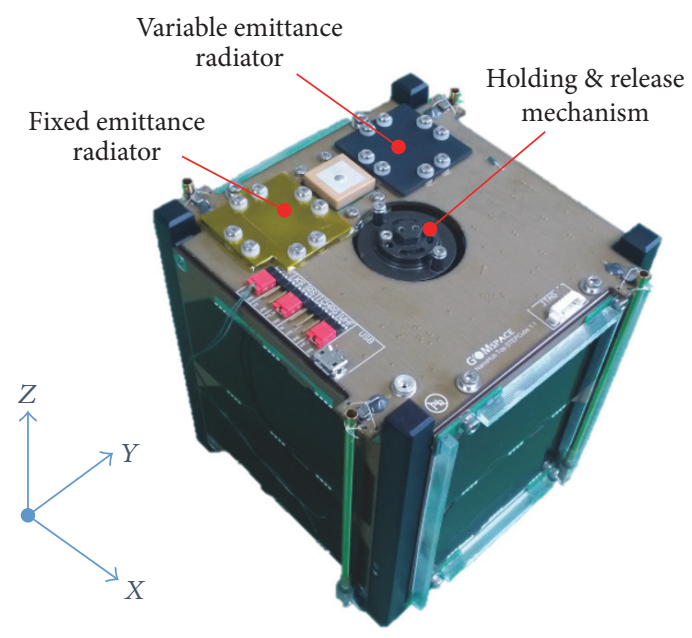

(a)

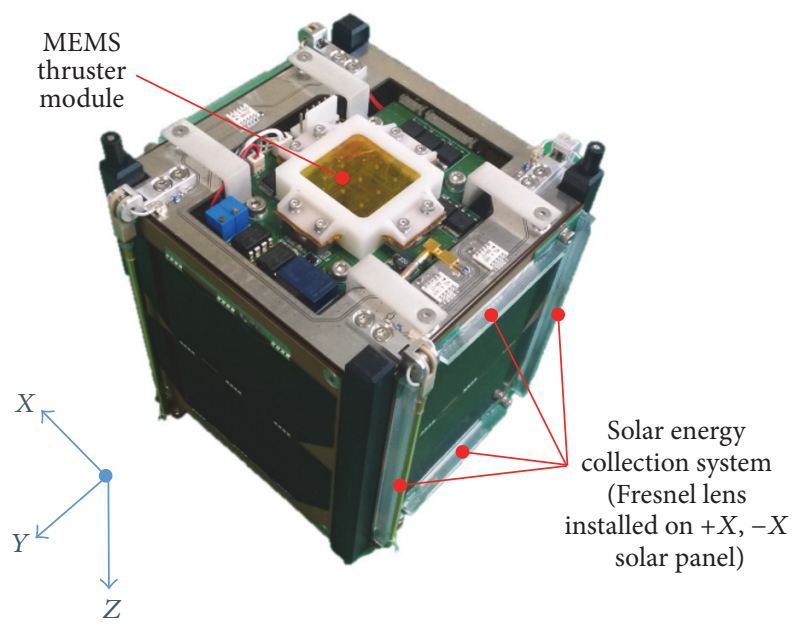

(b)

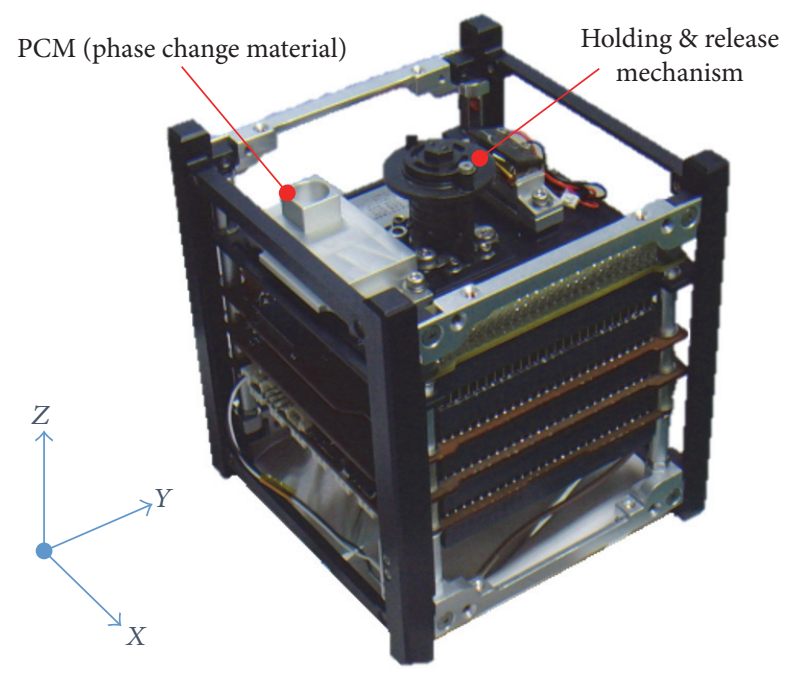

(c)

FIGURE 1: Configuration and payload accommodation of the STEP Cube Lab. ((a) external view from the $+Z$ axis, (b) external view from the $-Z$ Axis, and (c) internal view from the $+Z$ axis).

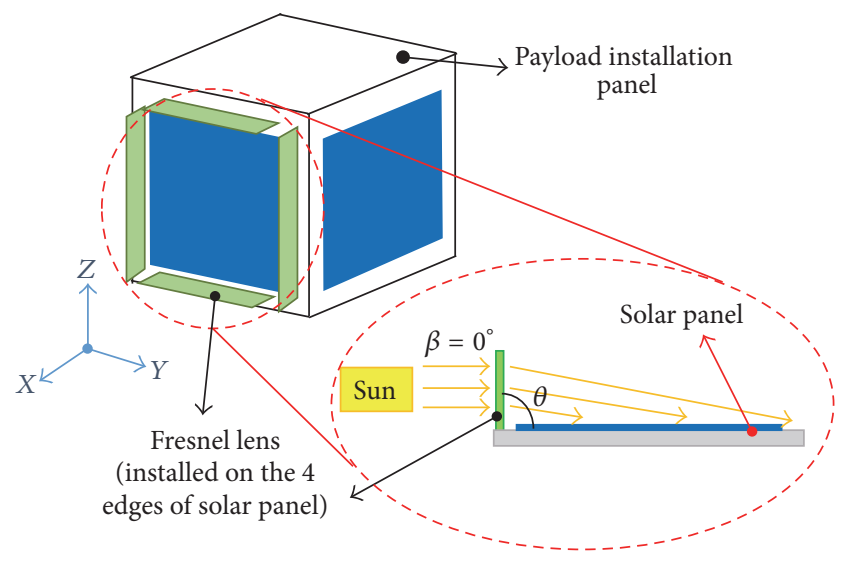

FIGURE 2: Schematic of the solar-energy collection system for cube satellite applications.

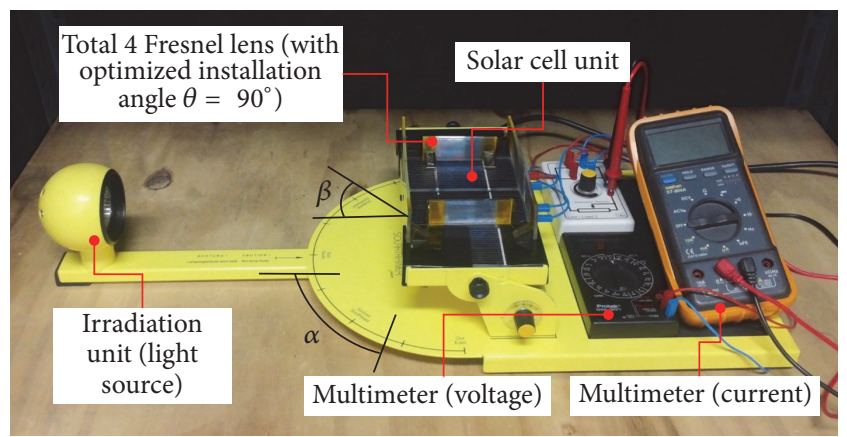

Figure 3: Power-measurement test set-up.

Figure 3. $\alpha$ is the horizontal rotation angle of the irradiation source, and $\beta$ is the incidence angle between the irradiation 


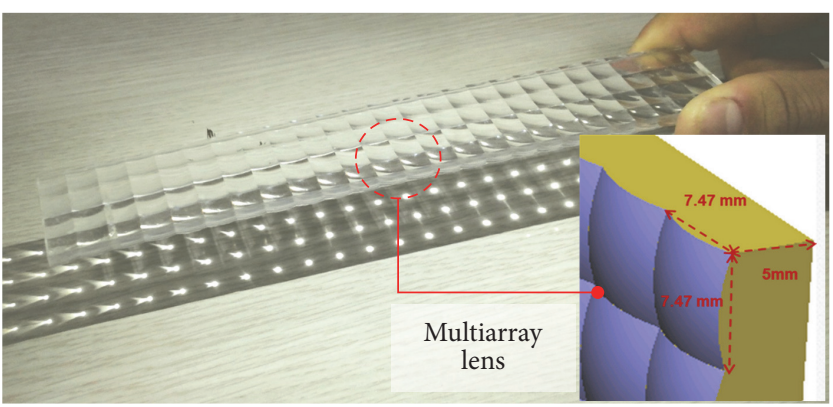

(a)

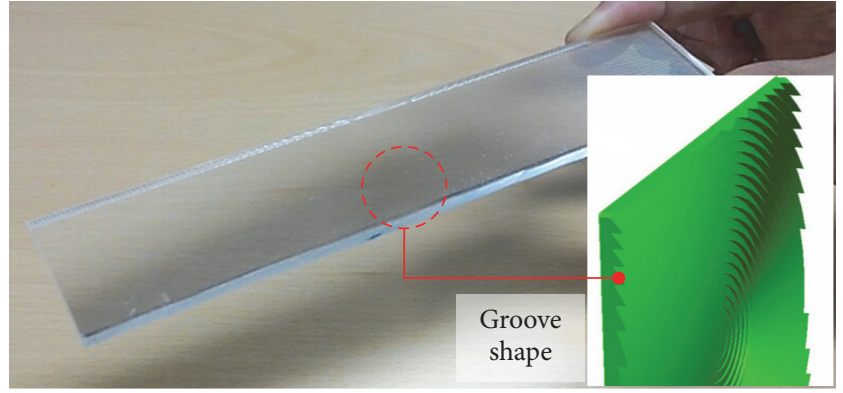

(b)

Figure 4: Commercial PMMA convex lenses ((a) Fresnel lens, (b) multiarray lens).

source and the solar panel. The angle $\beta$ represents the angle between the sun vector and the solar panel of the satellite inorbit; the angle values of $0^{\circ}$ and $90^{\circ}$ correspond to the worst and best conditions, respectively, for generating power.

In the power-measurement test, a commercial convex Fresnel lens was used to verify the effectiveness of the proposed solar-energy collection system. For a comparison of the power generation performance, a commercial convex multiarray lens used in a previous study by Oh and Park [25] was applied. Figures 4(a) and 4(b) show the configurations of the commercial convex Fresnel and multiarray lenses, respectively. Table 2 presents the specifications of the convex lenses. The lenses were made of PMMA and had a transmission efficiency of $92 \%$ with wavelengths ranging from 400 to $1,100 \mathrm{~nm}$. They were installed on the edge of the solar panel of the simulator, as shown in Figure 3, to enhance the power generation efficiency of the solar panel even under the worst angle condition of $\beta=0^{\circ}$, by effectively collecting the solar energy and redirecting it onto the solar panel. Through preliminary tests, the angle $\theta$ of the Fresnel lens system, which corresponds to the inclination angle between the Fresnel lens and the solar panel, was optimized to $90^{\circ}$, and that of the convex multiarray lens was optimized to $30^{\circ}$. The tests were conducted in a darkroom to prevent the influence of unintended light from external light sources on the solar cells. In this test, we measured the voltage and current from the solar panel, both with and without the PMMA lenses, under various incidence-angle conditions.

\section{Power-Measurement Test Results}

To verify the effectiveness of the proposed solar-energy collection system employing the Fresnel lens system under various conditions of the sun incidence angle, the currentvoltage $(I-V)$ characteristic curves of the solar panel were obtained both with and without the Fresnel lens system according to the variation in the incidence angle of the light source. In addition, power generation performance of the Fresnel lens system was compared to the results of the multiarray lens system.

Figure 5 shows the test configuration that simulates $\beta=0^{\circ}$ and $\alpha=90^{\circ}$, which is the worst sun incidence-angle condition on the solar panel. The $I-V$ curves of the solar panels obtained

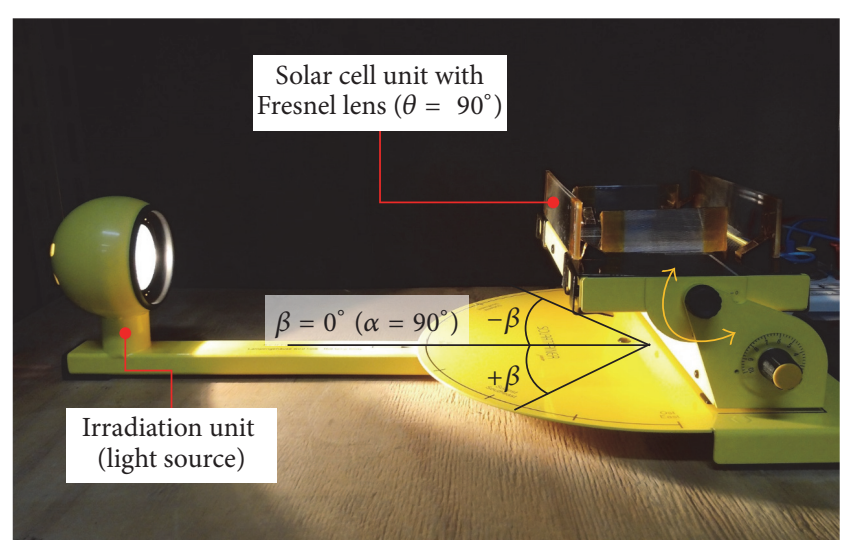

FIGURE 5: Configuration of the power-measurement test with $\beta=0^{\circ}$ and $\alpha=90^{\circ}$.

with and without the Fresnel lens system at $\beta=0^{\circ}$ and $\alpha=90^{\circ}$ are shown in Figure 6 . The $I-V$ curves obtained for the multiarray lens system are also plotted in the figure in order to make a comparison with the Fresnel lens system. The test results of both lenses with an optimized angle of $\theta$ show a much higher power generation performance than those obtained without lenses because the lens can effectively redirect and illuminate the solar energy to the solar panels under the worst sun incidence-angle condition. The maximum power of the Fresnel lens system, calculated from the $I-V$ curve, was $25.1 \mathrm{~mW}$, which is 9.4 times greater than that of the multiarray lens system. This indicates that the Fresnel lens installed at the optimized inclination angle of $\theta=90^{\circ}$ is more effective for enhancing the power generation performance of the solar panel by efficiently collecting and redirecting a much larger amount of the solar energy than the multiarray lens installed with $\theta=30^{\circ}$.

Figure 7 shows the test results obtained when the $\beta$ angle was varied from $-30^{\circ}$ to $90^{\circ}$, and when $\alpha$ was fixed as $90^{\circ}$, in order to evaluate the performance variation of the solar panel both with and without the Fresnel lens system over a wide range of sun incidence angles. The results for the multiarray lens system are also plotted here for comparison. The range of $\beta$ from $-30^{\circ}$ to $0^{\circ}$ is the worst condition with regard to the power generation of the solar panel because it cannot absorb 
TABLE 2: Specification of commercial PMMA lenses.

\begin{tabular}{lcc}
\hline Name & Convex Fresnel lens & Convex multiarray Lens \\
\hline Material & PMMA (polymethyl methacrylate) \\
Transmission efficiency & $92 \%($ at $400-1100 \mathrm{~nm})$ & $-70^{\circ} \mathrm{C} \sim 80^{\circ} \mathrm{C}$ \\
Allowable service temperature & $30 \mathrm{~mm} \times 189 \mathrm{~mm} \times 3 \mathrm{~mm}$ & $30 \mathrm{~mm} \times 189 \mathrm{~mm} \times 5 \mathrm{~mm}$ \\
Dimension & $182 \mathrm{~mm}$ & $29.88 \mathrm{~mm}$ \\
Focal length & & \\
\hline
\end{tabular}

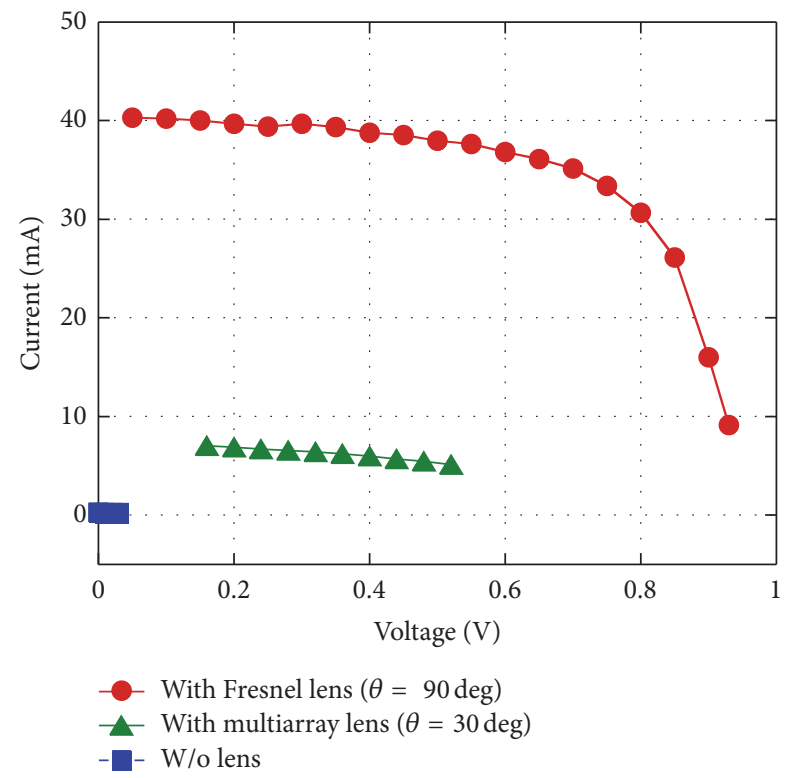

FIGURE 6: Results of the power-measurement test with $\beta=0^{\circ}$ and $\alpha=90^{\circ}$.

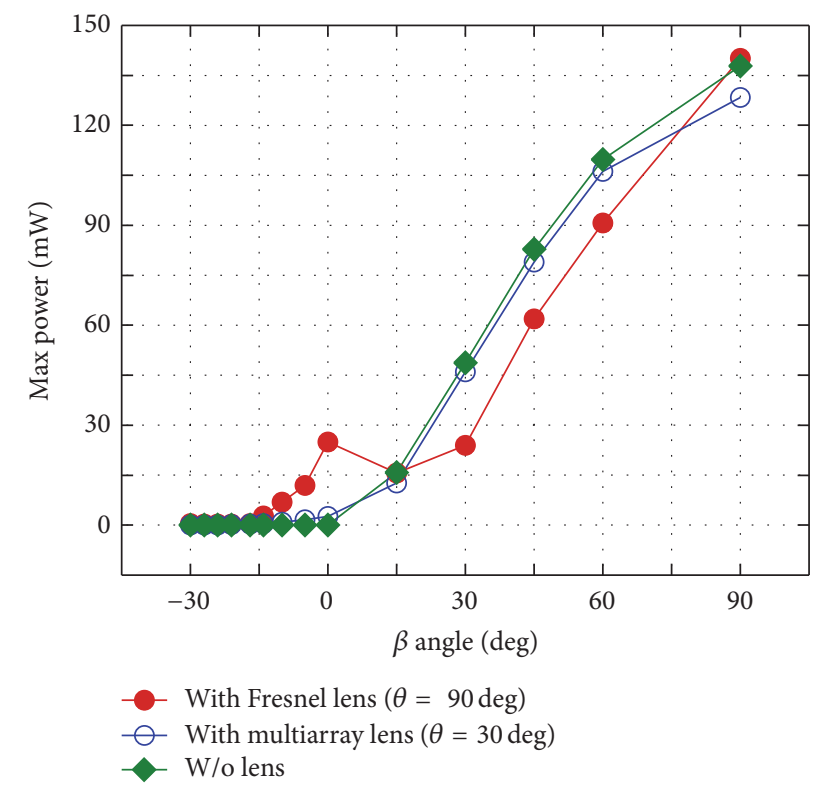

FIgURE 7: Results of power-measurement test with varying $\beta$ and $\alpha=90^{\circ}$. the solar energy directly. However, the Fresnel lens system can effectively generate a much higher power than the other systems under the worst incidence-angle condition from $-30^{\circ}$ to $15^{\circ}$. In particular, the Fresnel lens system exhibited the highest performance at $\beta=0^{\circ}$. These results indicate that the proposed Fresnel lens system might be effective for power generation in a three-axis stabilization attitude control satellite when the dedicated solar panel faces the sun. In contrast, as $\beta$ increases beyond $15^{\circ}$, under a favorable incidence-angle condition for the solar panel, the performance obtained using the Fresnel lens system decreases although the performance obtained using the multiarray lens system is similar to that without the lens system. This is because of the shadowing effect of the lens system installed on the edge of the solar panel with a transmission efficiency of $92 \%$. However, the test results for the Fresnel lens system with $\beta=90^{\circ}$ under the best sun-incidence angle condition showed almost identical performance to the configuration without the lens system, and the multiarray lens system yielded a 5.5\% decrease in the power generation performance. This is attributed to the minimization of the performance degradation by the transmission loss of the lens array at $\beta=90^{\circ}$, which is the best condition for power generation on-orbit. These test results indicate that the power generation performance of the solarenergy collection system utilizing the PMMA lens system depends on the sun-incidence angle. Therefore, the effects induced by the attitude control strategies of the satellite, such as passive permanent-magnet stabilization and active threeaxis attitude control, under sun incidence-angle variation were investigated through an on-orbit power simulation, as discussed in the last chapter of this paper.

Figure 8 shows the test configuration for validating the effectiveness of the proposed strategy with $\beta$ fixed as $0^{\circ}$ and $\alpha$ varying between $67.5^{\circ}, 45^{\circ}, 22.5^{\circ}$, and $0^{\circ}$. Figures 9 (a) and 9 (b) compare the test results, that is, the $I-V$ curves between the Fresnel and multiarray lens systems. The test results obtained without the lens systems are also plotted in both figures. The solar-energy collection system utilizing the PMMA lens system exhibited a much higher performance than that without a lens system. In addition, as the $\alpha$ angle decreased, the performance of both lens systems tended to decrease until $\alpha=22.5^{\circ}$, but the performances increased again at $\alpha=0^{\circ}$. The calculated maximum power of the Fresnel lens system under the worst condition of $\alpha=22.5^{\circ}$ was $1.77 \mathrm{~mW}$. This is almost twice the power generation performance of the multiarray lens system. The test results indicate that the proposed system employing the Fresnel lens is much more 
TABLE 3: Summary of the power-measurement test results.

\begin{tabular}{|c|c|c|c|c|}
\hline \multicolumn{2}{|c|}{ Incidence angle } & \multicolumn{3}{|c|}{$P_{\max }(\mathrm{mW})$} \\
\hline$\alpha$ & $\beta$ & w/o PMMA lens & With Fresnel lens & With multiarray lens \\
\hline $67.5^{\circ}$ & \multirow{4}{*}{$0^{\circ}$} & \multirow{4}{*}{0.0032} & 21 & 1.98 \\
\hline $45^{\circ}$ & & & 1.79 & 1.41 \\
\hline $22.5^{\circ}$ & & & 1.77 & 0.90 \\
\hline $0^{\circ}$ & & & 7.63 & 1.01 \\
\hline \multirow{12}{*}{$90^{\circ}$} & $-30^{\circ}$ & 0.0003 & 0.42 & 0.014 \\
\hline & $-25^{\circ}$ & 0.0003 & 0.35 & 0.08 \\
\hline & $-20^{\circ}$ & 0.0003 & 0.35 & 0.16 \\
\hline & $-15^{\circ}$ & 0.0003 & 2.86 & 0.48 \\
\hline & $-10^{\circ}$ & 0.0003 & 7.02 & 0.88 \\
\hline & $-5^{\circ}$ & 0.0003 & 14.02 & 1.66 \\
\hline & $0^{\circ}$ & 0.0032 & 25.05 & 2.66 \\
\hline & $15^{\circ}$ & 15.79 & 15.67 & 12.62 \\
\hline & $30^{\circ}$ & 48.778 & 23.93 & 46 \\
\hline & $45^{\circ}$ & 82.77 & 61.95 & 79.04 \\
\hline & $60^{\circ}$ & 109.76 & 90.73 & 106.16 \\
\hline & $90^{\circ}$ & 137.87 & 140.2 & 128.35 \\
\hline
\end{tabular}

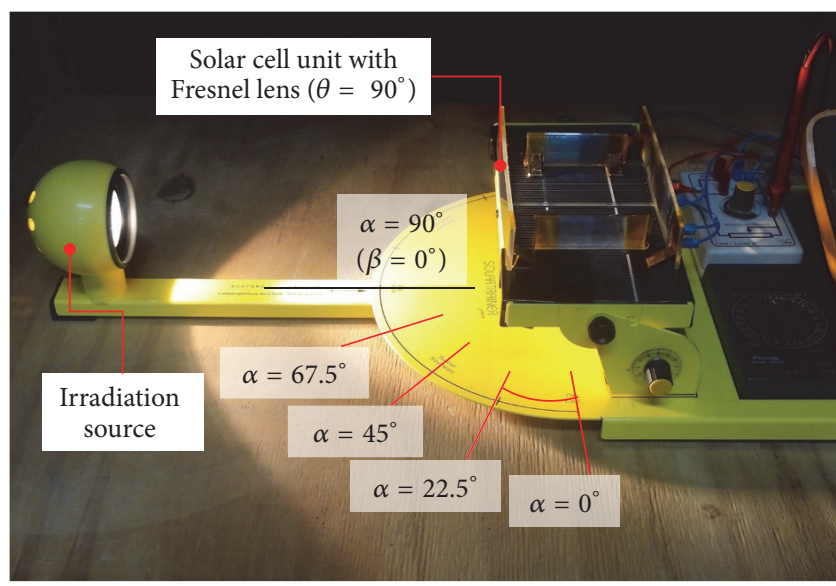

FIGURE 8: Configuration of the power-measurement test with $\beta=0^{\circ}$ and varying $\alpha$.

effective for power generation than the multiarray lens system with a varying $\alpha$ angle.

Table 3 summarizes the calculated maximum power from the power-measurement test results of $V_{\max }$ and $I_{\max }$ for each test condition. The proposed solar-energy collection system using the Fresnel lens had a much higher power generation performance in almost all the test cases, except when the sun incidence angle $\beta$ exceeded $15^{\circ}$. Particularly, the highest power generation performance was observed at $\beta=0^{\circ}$ and $\alpha=90^{\circ}$. The power generation performance of the Fresnel lens system was 7,828 times better than without a solarenergy collection system and 9.4 times greater than that of the multiarray lens system. However, when the incidence angle $\beta$ exceeded $15^{\circ}$, the performance obtained with the Fresnel lens system was lower than that without the lens systems, and the multiarray lens system exhibited results similar to those obtained without the lens systems. These phenomena will be considered for the on-orbit prediction of the power generation efficiency of the solar-energy collection system with various attitude control strategies.

The halogen lamp used in this study is an uncollimated light source. However, the Fresnel lens used in this study basically redirects the collected light towards its focal point. By applying the Fresnel lens in a way that was proposed in this study, the solar energy collected to the Fresnel lens is spread over the area of solar panel without forming a focal point on it. In addition, the power measurement test using a xenon lamp has been performed by Oh and Park [25] to investigate additional spectral features of light source related to an air mass zero (AM0) solar irradiation because this more effectively simulates the solar energy in a wide solar wavelength spectrum compared to the halogen lamp. In the test, they used a multiarray lens, which has the same dimensions and material as the one used in this study. The test results were obtained under the incidence angle of $\beta=0^{\circ}$ and $\alpha=90^{\circ}$ condition. The results indicated that much higher power generation can be obtained using xenon lamp compared to the halogen lamp. The test results indicate that the PMMA Fresnel lens is effective over the solar wavelength spectrum because its principle to collect and illuminate the solar energy onto the solar panel is similar as that of the multiarray lens. These features indicate that the SEC system proposed in this study is feasible for efficient power generation on-orbit over the wavelength spectrum, although the test results were obtained under the condition using uncollimated light source. Therefore, we judged that the proposed SEC system will be feasible under a collimated light source or an actual sunlight in-orbit. In the near future, this 


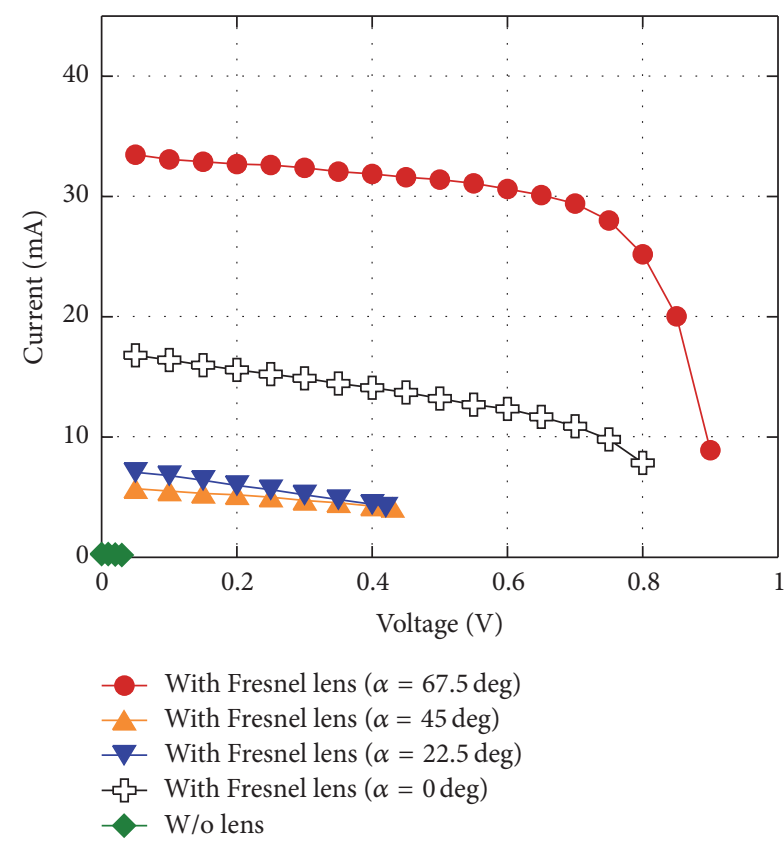

(a)

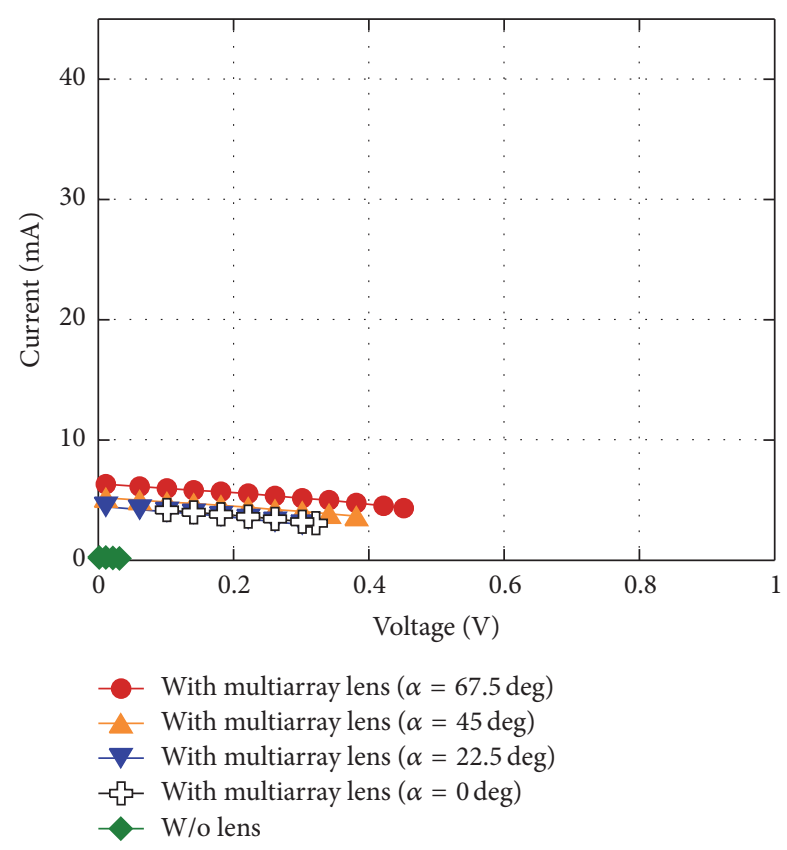

(b)

FIGURE 9: Results of the power-measurement test with $\beta=0^{\circ}$ and varying $\alpha$ ((a) Fresnel lens, (b) multiarray lens).

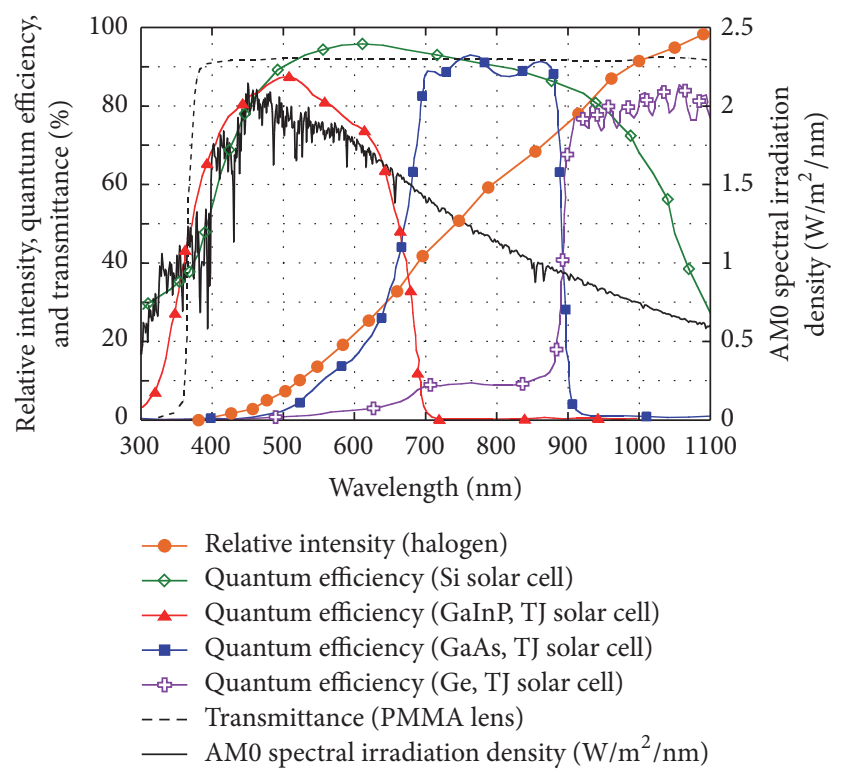

FIGURE 10: Spectral characteristics of the PMMA lens, solar cells, and halogen lamp with respect to AM0 solar irradiation.

will be verified by an on-orbit power measurement test of the SEC system using the cube satellite STEP Cube Lab.

\section{Assessment of Applicability of a PMMA Lens for a Solar-Energy Collection System}

To investigate the technical applicability of the PMMA lens for the solar-energy collection system, the transmittance of the PMMA lens, the spectral features of the halogen lamp light source, and the Si solar cell with respect to the air mass zero (AM0) environment used in the power-measurement test were analyzed, as these features are strongly related to the power generation efficiency of the proposed system in the solar wavelength spectrum on-orbit. Figure 10 shows the relative intensity of the halogen lamp, the quantum efficiency of the Si and triple-junction GaAs solar cells, the transmittance of the commercial PMMA lens, and the AM0 spectral irradiation density. As shown in the figure, the Si solar cell used in the test effectively simulates the spectral features of the triple-junction GaAs solar cell, which has been widely used for space programs. The halogen lamp used in this study has limitations for simulating solar-energy over a wide wavelength spectrum, especially at ultraviolet wavelengths. However, the PMMA lens is capable of transmitting solarenergy over a wide wavelength range, as shown in Figure 10. In addition, it covers the wide wavelength range of the triple-junction GaAs solar cell using multiple semiconductor materials GaInP, GaAs, and Ge. The test results also show a higher power generation performance, although the halogen lamp light source has limitations for simulating the spectral features of the solar cell and the AM0 spectral irradiation density. These assessments indicate that the solar-energy collection system using the PMMA lens is effective for efficient power generation on-orbit over the given wavelength spectrum.

The outgassing requirements of the material selection for space applications are a total mass loss (TML) less than $1.0 \%$ and a controlled volatile condensable material (CVCM) less than 0.1\%, according to the ASTM E595 standard [28]. Therefore, we performed an outgassing-measurement test on 
TABLE 4: Material and thermooptical properties of the PMMA lens.

\begin{tabular}{lcc}
\hline Property & Parameter & Value \\
\hline \multirow{2}{*}{ Thermooptical property } & Absorptivity $(a)$ & 0.04 \\
& Emissivity $(\epsilon)$ & 0.04 \\
\hline \multirow{3}{*}{ Material property } & Conductivity $(\mathrm{W} / \mathrm{m} / \mathrm{k})$ & 1.5 \\
& Density $\left(\mathrm{kg} / \mathrm{m}^{3}\right)$ & 2210 \\
& Specific heat $(\mathrm{J} / \mathrm{kg} / \mathrm{k})$ & 0.198 \\
\hline
\end{tabular}

the PMMA lens. The test apparatus and procedures were in accordance with the ASTM E595 standard. In the TML measurement test, we used four samples of PMMA lens specimen with dimensions of $10 \mathrm{~mm} \times 10 \mathrm{~mm} \times 1 \mathrm{~mm}$. The measured TML and CVCM values were $1.028 \%$ and $0.038 \%$, respectively. The TML value was slightly over the requirement of $1.0 \%$, but the difference was at most $0.078 \%$. Therefore, we judge that this PMMA lens is applicable for the STEP cube mission.

The allowable service-temperature range of the PMMA lens given by the vendor is $-70^{\circ} \mathrm{C} \sim 80^{\circ} \mathrm{C}$, as shown in Table 2 . Therefore, to investigate the survivability of PMMA, the lens integrated on the solar panel, we performed an onorbit thermal analysis under the worst hot and cold orbital conditions by using the commercial on-orbit thermal analysis software of Thermal Desktop [29] and SINDA/Fluint [30]. Table 4 presents the material and thermooptical properties of the PMMA lens. Table 5 shows the orbit and thermal parameters used as inputs for the analysis. In addition, we assumed that the satellite performs two cycles of rotation per orbit by using the passive permanent magnet attitudestabilization method. The results of the on-orbit thermal analysis are summarized in Table 6. The maximum and minimum temperatures of the PMMA lens calculated in the on-orbit thermal analysis under the worst hot and cold conditions were $24.7^{\circ} \mathrm{C}$ and $-38.4^{\circ} \mathrm{C}$, respectively. The results indicate that the PMMA lens would operate safely within the allowable temperature conditions on-orbit and would have a sufficient temperature margin of $31.6^{\circ} \mathrm{C}$ with regard to the allowable temperature thresholds.

\section{On-Orbit Prediction of Power Generation Efficiency}

The power-measurement test results demonstrate that the power generation efficiency of the proposed solar-energy collection system using the PMMA lens depends on the sun incidence angle. This means that the attitude control strategy of the satellite is one of the most important parameters for determining the power generation efficiency of the satellite, as the incidence angle $\beta$ between the sun vector and the satellite varies continuously owing to the revolution and rotation of the satellite. Therefore, we predicted the on-orbit power generation efficiency according to the attitude control strategies of a satellite with passive permanent-magnet stabilization, the active three-axis stabilization method, and the passive gravity-gradient attitude stabilization method. This prediction was performed using STK. The power-measurement test

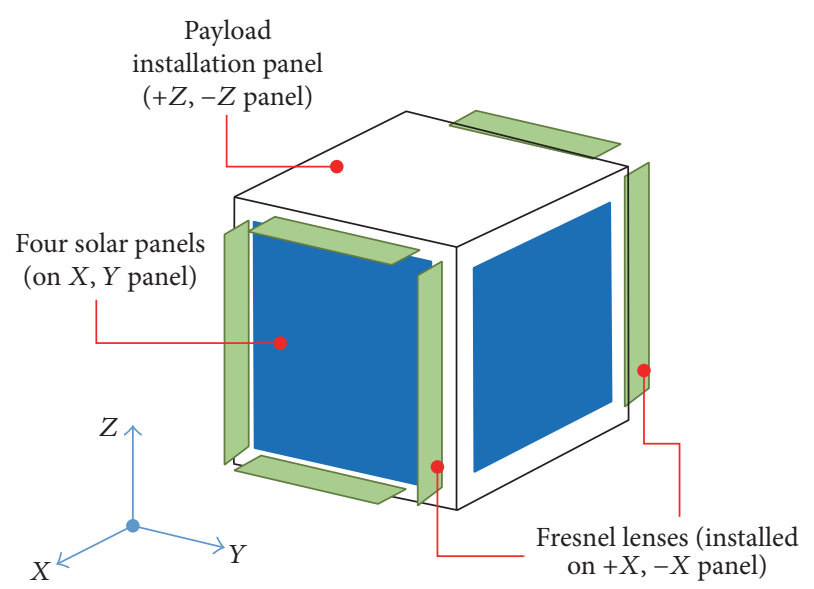

FIGURE 11: $1 \mathrm{U}$ standardized cube satellite model employing the solar-energy collection system.

results described in this study were used as input data for the prediction. Table 7 summarizes the simulation parameters used for the prediction. In the simulation, we assumed the satellite to be operated in a sun-synchronous orbit at an altitude of $600 \mathrm{~km}$. The orbital periods of sunlight and eclipse during the on-orbit operation were 3,682 and 2,119 seconds, respectively. The average incoming solar intensity was $1,358 \mathrm{~W} / \mathrm{m}^{2}$ and the conversion efficiency of the solar cell was $30 \%$.

Figure 11 illustrates an example of the $1 \mathrm{U}$ cube satellite with the proposed solar-energy collection system. The satellite employs a total of four solar panels in the $X$ and $Y$ side panels because it is assumed that the $Z$ panels are used for other appendages such as the antenna or payloads. We also assumed that PMMA lens systems were installed on the $+X$ and $-X$ panels. Figure 12 shows the attitude profiles of the satellite with different attitude control strategies. Figure 12(a) illustrates the on-orbit profiles of the satellite with passive permanent-magnet stabilization, which involved two cycles per orbit whereby the satellite aligned itself with the local earth magnetic field. Therefore, the incidence angle between the sun vector and the solar panels varied continuously, as shown in Figure 12(a). In the case of active three-axis attitude control, the $+Y$ panel of the satellite maintained the attitude of the satellite toward the sun, as shown in Figure 12(b). In the case of the passive gravity-gradient attitude stabilization method, the $-Z$ panel of the satellite maintained the attitude of the satellite toward the direction of earth's center in-orbit, as shown in Figure 12(c). In the estimation, the incidence angle $\beta$ between the sun vector and the solar panels and the power generated by each solar panel were calculated using STK. To estimate the power generation of the solar cells with the PMMA lens system, the power-measurement test data, as summarized in Table 3, were used for a power calculation while considering the variation of the sun incidence angle with respect to the solar cells with the PMMA lens. In the case of the 3-axis active attitude control method, we did not consider a counterbalancing effect due to the power consumption for maintaining attitude of the satellite in-orbit 


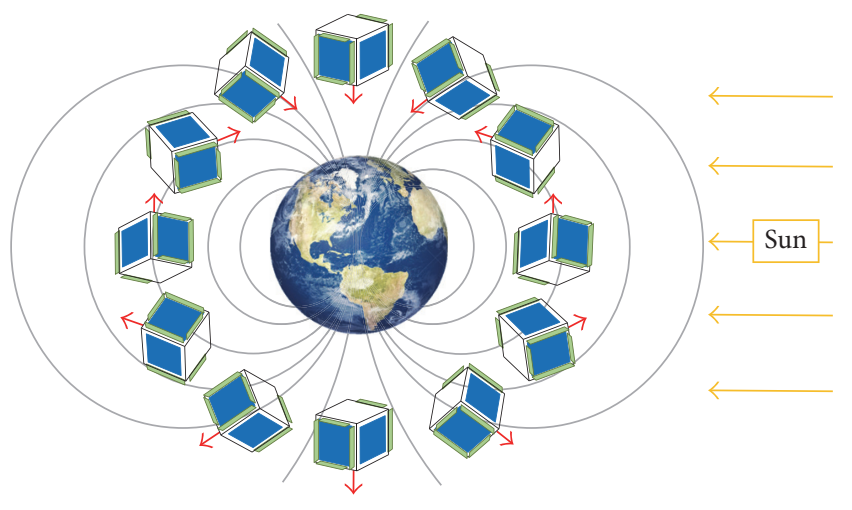

$\longleftarrow$ Magnetic stabilization $(+Z$ panel $)$

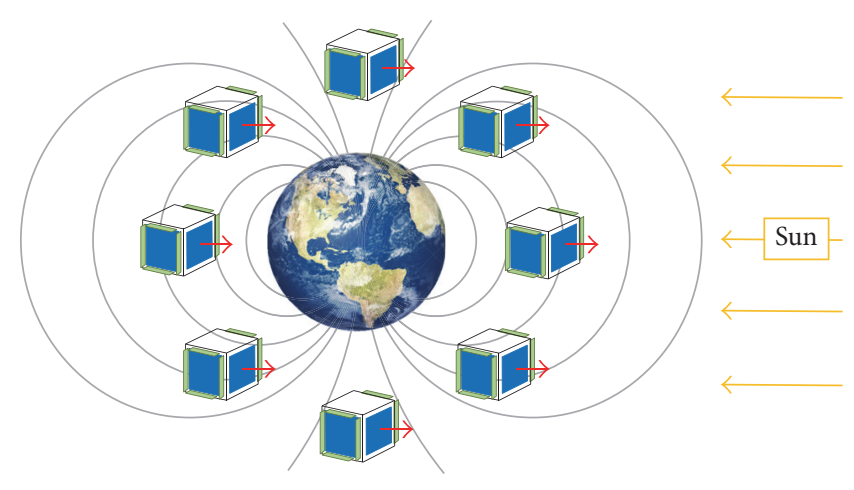

$\longleftarrow$ Sun pointing $(+Y$ panel $)$

(a)

(b)

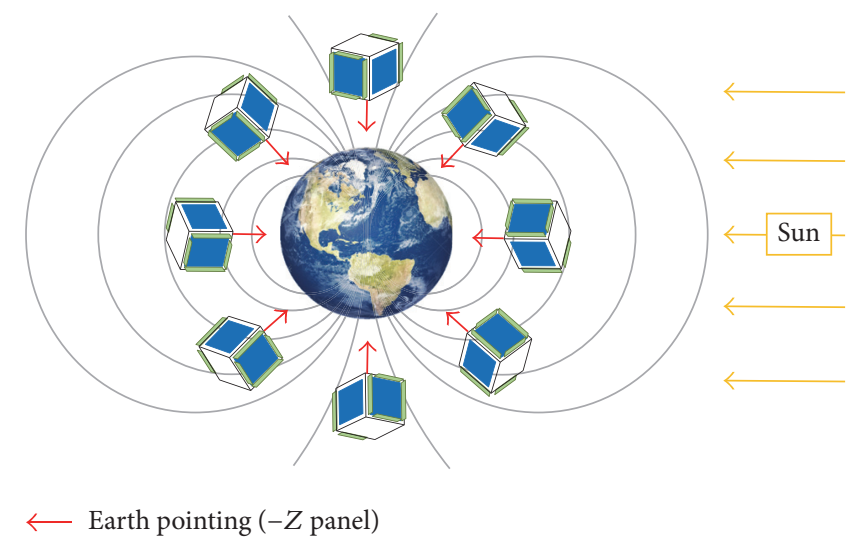

(c)

FIGURE 12: Attitude profile of the satellite ((a) passive attitude-stabilization method using permanent magnet and hysteresis rods, (b) active three-axis attitude control method, and (c) gravity-gradient stabilization method).

TABLE 5: Conditions for the on-orbit thermal analysis.

\begin{tabular}{lcc}
\hline Orbit parameter & Worst hot case & Worst cold case \\
\hline Orbit type & & Sun-synchronous (Circular) \\
Inclination (deg.) & 97.78 \\
Altitude (km) & 600 \\
Orbital period (sec) & 5801.23 \\
LTAN (local time ascending node) & 1420 & $12: 00$ AM \\
Solar flux $\left(\mathrm{W} / \mathrm{m}^{2}\right)$ & 0.35 & 1287 \\
Albedo & 249 & 0.3 \\
IR planet shine $\left(\mathrm{W} / \mathrm{m}^{2}\right)$ & Winter solstice & 227 \\
Solar term & & Summer solstice
\end{tabular}

because the objective of this study is to confirm the feasibility of the SEC system using Fresnel lens system by comparing its power generation performance of the cube satellite on-orbit with that using the multiarray lens.

Figure 13 shows the on-orbit time profiles of the power generation of the satellite with and without the Fresnel lens system for the permanent-magnet stabilization method. The on-orbit profile with the multiarray lens system is also plotted here for comparison. The results indicate that the power generation of the satellites with both PMMA lens systems depends on the variation of the sun incidence angle $\beta$ with respect to the solar panel because of the revolution and rotation of the satellite according to the attitude control strategy, particularly for the Fresnel lens system. Consequently, the estimated total power generation of the satellite with the Fresnel lens system is $2.22 \mathrm{Wh}$, which is $10.13 \%$ and $9.8 \%$ 
TABLE 6: Summary of the on-orbit thermal analysis results.

\begin{tabular}{lccccc}
\hline Component & \multicolumn{2}{c}{ Worst cold case } & \multicolumn{2}{c}{ Worst hot case } & \multicolumn{2}{c}{ Margin with respect to } \\
& $T_{\min }\left({ }^{\circ} \mathrm{C}\right)$ & $T_{\max }\left({ }^{\circ} \mathrm{C}\right)$ & $T_{\min }\left({ }^{\circ} \mathrm{C}\right)$ & $T_{\max }\left({ }^{\circ} \mathrm{C}\right)$ & $T_{\min } / T_{\max }\left({ }^{\circ} \mathrm{C}\right)$ \\
\hline PMMA lens & -38.4 & 12.94 & -33.2 & 24.7 & $-31.6 /+55.3$ \\
\hline
\end{tabular}

TABLE 7: Conditions for the on-orbit power generation prediction.

\begin{tabular}{ll}
\hline Parameter & Condition \\
\hline Orbit & Sun-synchronous, $600 \mathrm{~km}$ altitude \\
Orbital period & $5801 \mathrm{~seconds}$ (sunlight/eclipse: $3682 / 2119$ seconds) \\
Solar intensity & $1358 \mathrm{~W} / \mathrm{m}^{2}$ \\
& (i) Passive attitude-stabilization using permanent magnet \\
Attitude control & (ii) Active three-axis attitude control \\
& (iii) Passive gravity-gradient attitude stabilization \\
Solar cell & Efficiency: $30 \%$ \\
Solar-energy collection system & Cell area: $60.36 \mathrm{~cm}^{2}$ (per panel) \\
\hline
\end{tabular}

TABLE 8: Results of the on-orbit power generation prediction.

\begin{tabular}{lccc}
\hline Parameter & w/o PMMA lens & With Fresnel lens & With multiarray Lens \\
\hline & Passive attitude-stabilization method using permanent magnet & 2.22 & 3.022 \\
Generated power $(\mathrm{Wh})$ & 2.017 & 33.04 & 30.08 \\
Solar cell efficiency $(\%)$ & 30 & 3 -axis active attitude control method & 3.34 \\
& 2.48 & 40.36 & 3.57 \\
Generated power $(\mathrm{Wh})$ & 30 & Passive gravity-gradient attitude stabilization method & 31.1 \\
Solar cell efficiency $(\%)$ & 2.25 & 2.32 & 2.16 \\
Generated power $(\mathrm{Wh})$ & 30 & & 28.72 \\
Solar cell efficiency $(\%)$ & &
\end{tabular}

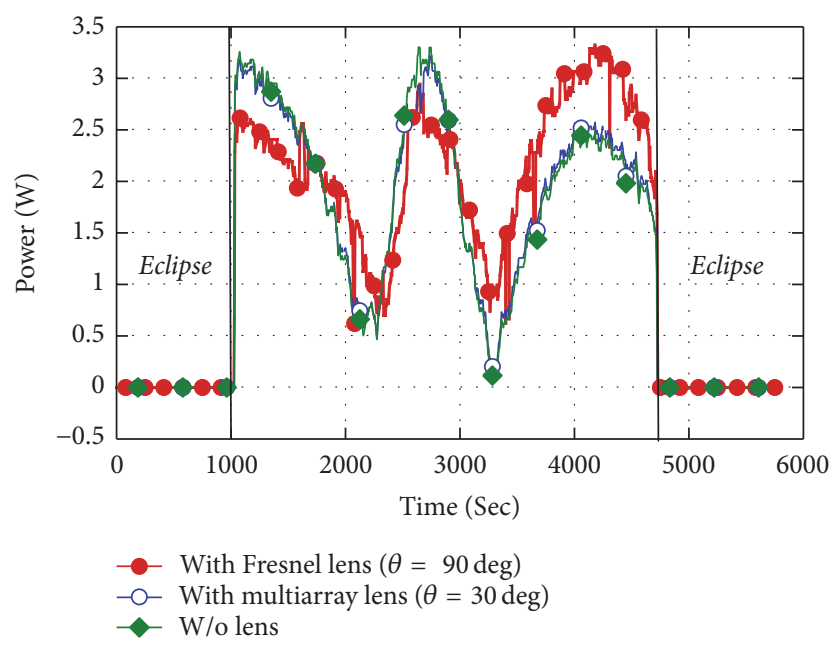

FIGURE 13: Results of the on-orbit power generation simulation of the satellite using the passive attitude-stabilization method with a permanent magnet and hysteresis rods. higher than that of the satellites without lens systems and with the multiarray lens system, respectively. These results indicate that the solar-energy collection system using the Fresnel lens can effectively enhance the power generation performance, despite the power degradation due to the presence of Fresnel lens system in front of the solar panels as shown in Figure 7.

Table 8 summarizes the estimated power generation, that is, the results of the on-orbit power generation prediction for each case. Figure 14 shows the on-orbit time profiles of the power generation of the satellite with and without the Fresnel lens system under the active three-axis attitude control strategy. For comparison, the on-orbit profiles of the satellite with the multiarray lens system are also plotted here. In this case, we assumed that the $+Y$ panel of the satellite maintained a sun-pointing attitude, as shown in Figure 12(b). Therefore, the $+X$ and $-X$ panels of the satellite were located at the worst positions with regard to power generation because they cannot absorb the solar energy from the sun at a sun incidence angle of $\beta=0^{\circ}$.

The power estimation results indicate that both of the lens systems effectively enhance the power generation of the 


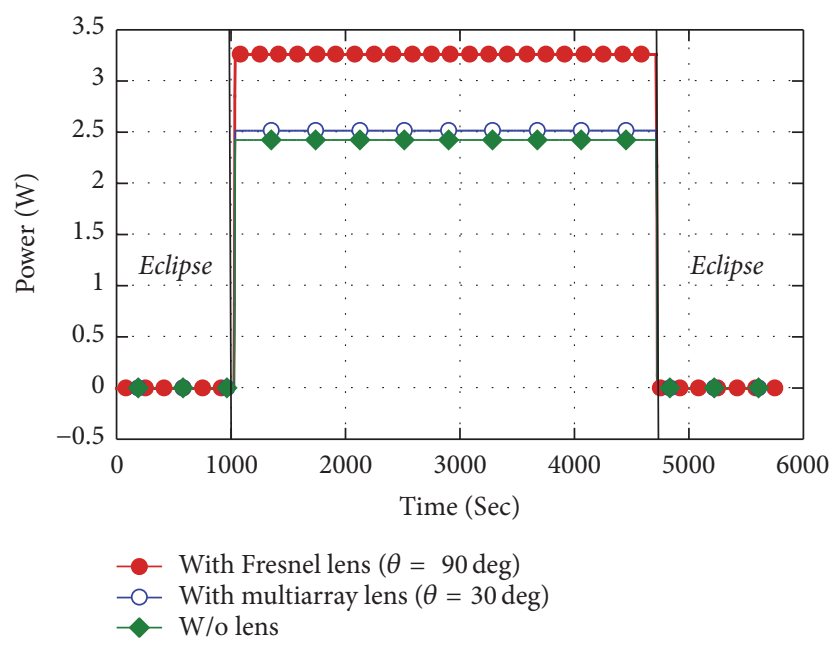

FIGURE 14: Results of the on-orbit power generation simulation of the satellite using the active three-axis attitude control method.

satellite. The total generated power with the Fresnel lens system was $3.34 \mathrm{Wh}$, which is almost $34.68 \%$ higher than that without a solar-energy collection system and 30\% higher than the multiarray lens system. In addition, when the threeaxis attitude control strategy was applied to the SEC system, the power generation performance was $50 \%$ higher than the permanent-magnet stabilization method. If additional solar panels are installed on the $+Z$ and $-Z$ panels, a much higher power generation performance can be expected.

Figure 15 shows the on-orbit time profiles of the power generation of the satellite with and without the Fresnel lens system under the passive gravity-gradient attitude stabilization method. For comparison, this figure also shows the onorbit time profile of the satellite with the multi-array lens system. The power estimation results indicate that both lens systems generate much lower power as compared to the other attitude control strategies. However, the Fresnel lens system showed much higher power generation than the multiarray lens system. The total generated power with the Fresnel lens system is $2.32 \mathrm{Wh}$, which is a $7.41 \%$ greater power generation than that of the satellite with the multiarray lens system. Therefore, we can say that the SEC system proposed in this study is also effective for enhancing power generation of cube satellite under the various attitude control strategies.

The primary goal of this study is to investigate the feasibility of using the Fresnel lens as a SEC system for cube satellite applications. Thus, the aging effects of the PMMA lens system in the space radiation environment were not investigated in this study. In the near future, this effect will be investigated through the STEP mission by obtaining power generation profiles using cube satellite in-orbit. In addition, since the SEC system proposed in this study was considered as a fixed configuration, the current size of the lens system shall be reduced to meet the dimensional constraints of the $1 \mathrm{U}$ cube satellite standard. However, this also involves a power degradation of the SEC system in-orbit. Alternatively, the SEC system can be considered as a deployable one to avoid such

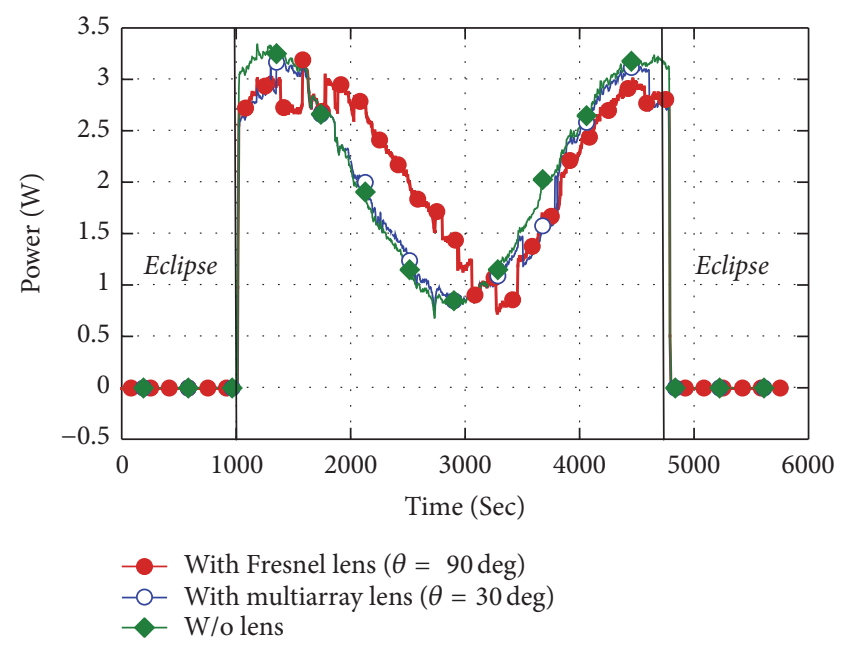

FIGURE 15: Results of the on-orbit power generation simulation of the satellite using the gravity-gradient attitude stabilization method.

power degradation. The most reasonable implementation method of the Fresnel lens system will be investigated in a future study considering dimension, mass, and power generation aspects.

\section{Conclusions}

This paper proposes a solar-energy collection system employing a Fresnel lens that is capable of providing an enhanced power generation efficiency for cube satellites with a limited area to install solar cells. Although the sun incidence angle with respect to the solar panel varies continuously because of the revolution and rotation of the satellite according to the attitude control strategy, the proposed system can effectively enhance the power generation efficiency of the satellite. The effectiveness of the proposed system was demonstrated by a power-measurement test using a solar simulator and a commercial PMMA Fresnel lens. The test results demonstrated that the Fresnel lens system installed on the edge of the solar panel at an optimized inclination angle is far more effective for power generation performance than the multiarray lens system even under the worst condition of the sun incidence angle with respect to the solar panel. Based on the test results, we predicted the on-orbit power generation efficiency of a cube satellite with the proposed solar-energy collection system using the commercial software STK. In the simulation, we confirmed an enhancement of $34.68 \%$ in the power generation performance of a cube satellite mploying a Fresnel lens with a three-axis attitude control strategy as compared to a satellite without the solar-energy collection system.

\section{Competing Interests}

The authors declare that they have no competing interests. 


\section{References}

[1] R. A. Deepak and R. J. Twiggs, "Thinking out of the box: space science beyond the CubeSat," Journal of Small Satellites, vol. 1, no. 1, pp. 3-7, 2012.

[2] V. Lappas, N. Adeli, L. Visagie et al., "CubeSail: a low cost CubeSat based solar sail demonstration mission," Advances in Space Research, vol. 48, no. 11, pp. 1890-1901, 2011.

[3] X. Li, Q. Schiller, L. Blum et al., "First results from CSSWE CubeSat: characteristics of relativistic electrons in the nearearth environment during the October 2012 magnetic storms," Journal of Geophysical Research: Space Physics, vol. 118, no. 10, pp. 6489-6499, 2013.

[4] R. Hoyt, J. Slostad, and R. Twiggs, "The Multi-Application Survivable Tether (MAST) experiment," in Proceedings of the 39th AIAA/ASME/SAE/ASEE Joint Propulsion Conference and Exhibit, July 2003.

[5] S. Arnold, J. Armstrong, C. Person, and M. Tietz, "QbXthe CubeSat experiment," in Proceedings of the 26th Annual AIAA/USU Conference on Small Satellites, SSC12-XI-4, pp. 1-15, Logan, Utah, USA, August 2012.

[6] J. Kim and W. Kevin, "Sun tracking controller for UKube-1 using magnetic torquer only," Automatic Control in Aerospace, vol. 19, no. 1, pp. 541-546, 2013.

[7] N. F. de Rooij, S. Gautsch, D. Briand et al., "MEMS for space," in Proceedings of the International Solid-State Sensors, Actuators and Microsystems Conference, pp. 17-24, June 2009.

[8] http://www.cubesatkit.com/.

[9] http://www.gaussteam.com/.

[10] http://www.gomspace.com/.

[11] K. Ryu, J.-G. Rhee, K.-M. Park, and J. Kim, "Concept and design of modular Fresnel lenses for concentration solar PV system," Solar Energy, vol. 80, no. 12, pp. 1580-1587, 2006.

[12] P. Pérez-Higueras, E. Muñoz, G. Almonacid, and P. G. Vidal, "High concentrator photovoltaics efficiencies: present status and forecast," Renewable and Sustainable Energy Reviews, vol. 15, no. 4, pp. 1810-1815, 2011.

[13] V. D. Rumyantsev, N. Y. Davidyuk, E. A. Ionova et al., "HCPV modules with primary and secondary minilens panels," in Proceedings of the 6th International Conference on Concentrating Photovoltaic (ICPV-6 '10), vol. 1277, pp. 97-100, Freiburg, Germany, April 2010.

[14] F. Morichetti, A. Righetti, G. Grasso, M. C. Ubaldi, and S. M. Pietralunga, "Gondola: trackless LCPV module for Si cells with low-aspect ratio and high energy rating," in Proceedings of the 38th IEEE Photovoltaic Specialists Conference (PVSC '12), pp. 957-960, Austin, Tex, USA, June 2012.

[15] L. Fraas, L. Minkin, J. Avery, H. X. Huang, J. Fraas, and P. Uppal, "Portable concentrating solar power supplies," in Proceedings of the 35th IEEE Photovoltaic Specialists Conference (PVSC '10), pp. 3025-3029, Honolulu, Hawaii, USA, June 2010.

[16] T. Uematsu, Y. Yazawa, T. Joge, and S. Kokunai, "Fabrication and characterization of a flat-plate static-concentrator photovoltaic module," Solar Energy Materials \& Solar Cells, vol. 67, no. 1, pp. 425-434, 2001.

[17] L. Desmet, A. J. M. Ras, D. K. G. De Boer, and M. G. Debije, "Monocrystalline silicon photovoltaic luminescent solar concentrator with $4.2 \%$ power conversion efficiency," Optics Letters, vol. 37, no. 15, pp. 3087-3089, 2012.

[18] M. D. Hughes, S.-Y. Wang, D.-A. Borca-Tasciuc, and D. A. Kaminski, "Analysis of ultra-thin crystalline silicon solar cells coupled to a luminescent solar concentrator," Solar Energy, vol. 122, pp. 667-677, 2015.

[19] T. Wang, J. Zhang, W. Ma et al., "Luminescent solar concentrator employing rare earth complex with zero self-absorption loss," Solar Energy, vol. 85, no. 11, pp. 2571-2579, 2011.

[20] P. Jenkins, M. Krasowski, N. Prokop et al., "TACSAT-4 solar cell experiment: advanced solar cell technologies in a high radiation environment," in Proceedings of the 34th IEEE Photovoltaic Specialists Conference (PVSC '09), Philadelphia, Pa, USA, June 2009.

[21] http://www.dss-space.com/index.html.

[22] S. Habraken, J.-M. Defise, J.-P. Collette, P. Rochus, P.-A. D'Odemont, and M. Hogge, "Space solar arrays and concentrators," Acta Astronautica, vol. 48, no. 5-12, pp. 421-429, 2001.

[23] W. Seboldt, M. Klimke, M. Leipold, and N. Hanowski, "European sail tower SPS concept," Acta Astronautica, vol. 48, no. 512, pp. 785-792, 2001.

[24] M. Mori, H. Kagawa, and Y. Saito, "Summary of studies on space solar power systems of Japan Aerospace Exploration Agency (JAXA)," Acta Astronautica, vol. 59, no. 1-5, pp. 132-138, 2006.

[25] H.-U. Oh and T. Park, "Experimental feasibility study of concentrating photovoltaic power system for cubesat applications," IEEE Transactions on Aerospace and Electronic Systems, vol. 51, no. 3, pp. 1942-1949, 2015.

[26] AGI, STK User's Manual Version 8.0.1 for PCs, Analytical Graphics Inc. (AGI), 2008.

[27] Y.-K. Chang, J.-H. Park, Y.-H. Kim, B.-Y. Moon, and M.-I. Min, "Design and development of HAUSAT- 1 picosatellite system (Cubesat)," in Proceedings of the International Conference on Recent Advances in Space Technologies (RAST '03), pp. 47-54, IEEE, November 2003.

[28] ASTM E595-15, "Standard Test Method for Total Mass Loss and Collected Volatile Condensable Materials from Outgassing in a Vacuum Environment," ASTM International, West Conshohocken, Pa, USA, 2015, https://www.astm.org/.

[29] “Thermal Desktop User's Manual, Ver. 5.5,” C\&R Technologies, Boulder, Colo, USA, February 2012.

[30] C\&R Technologies, SINDA/FLUINT User's Manual, Version 5.5, C\&R Technologies, Boulder, Colo, USA, 2011. 


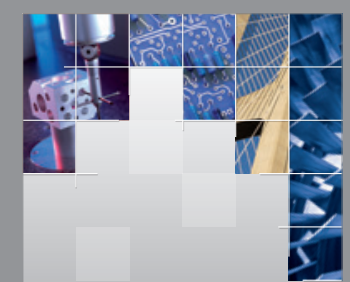

\section{Enfincering}
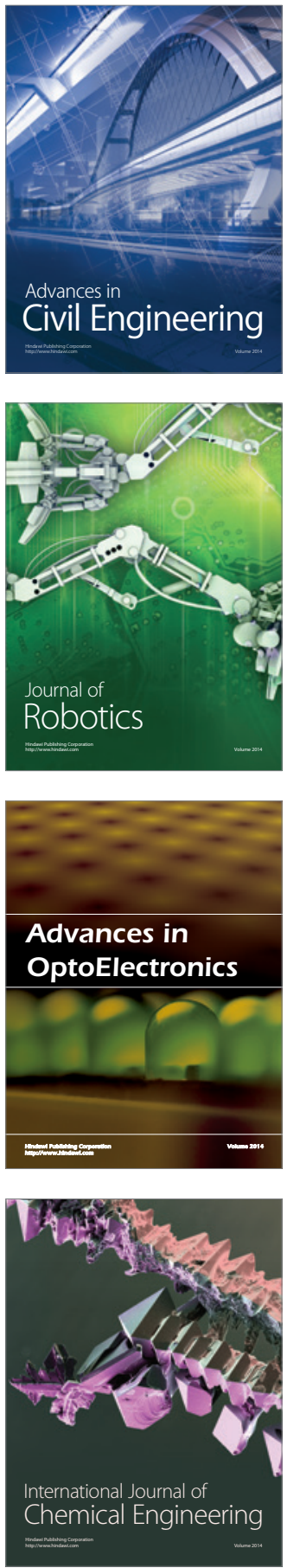

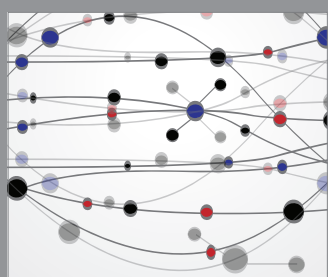

The Scientific World Journal

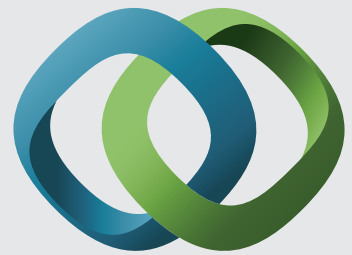

\section{Hindawi}

Submit your manuscripts at

https://www.hindawi.com
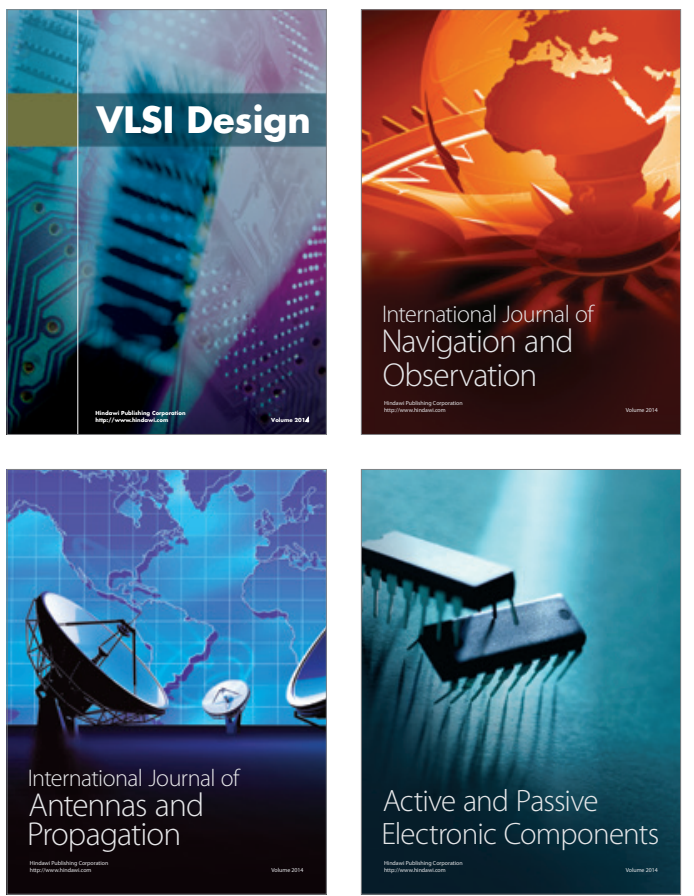
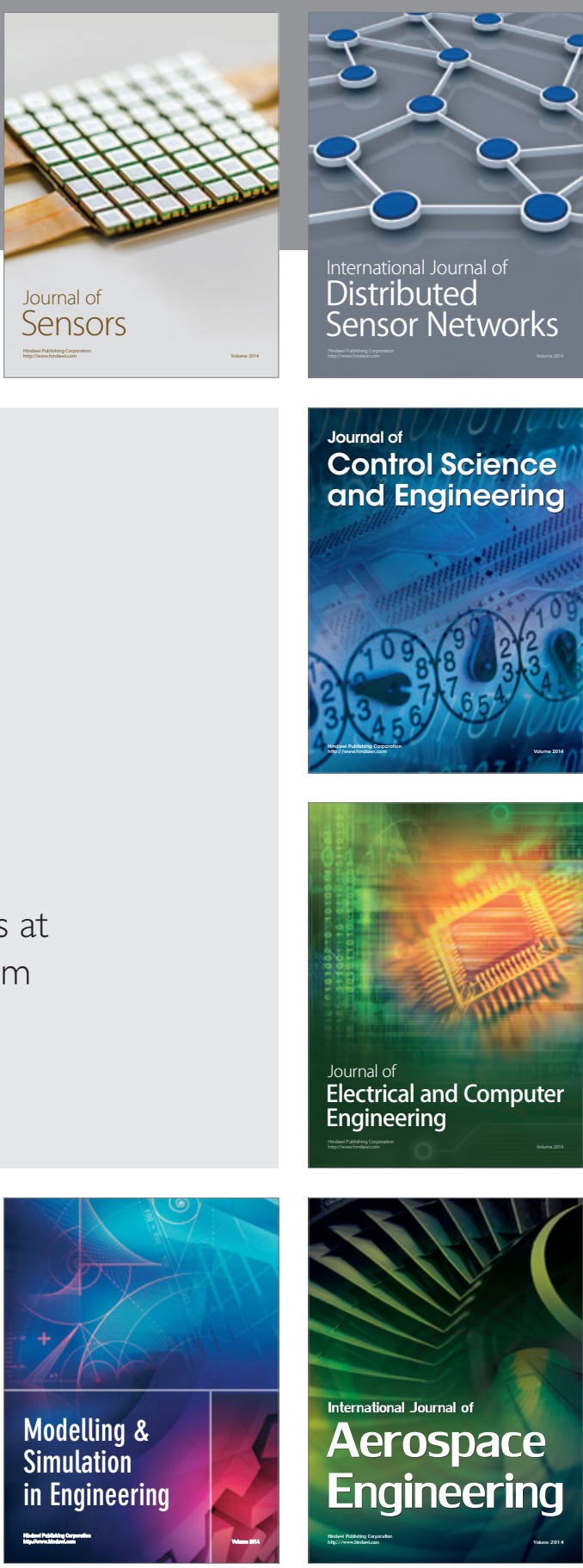

International Journal of

Distributed

Sensor Networks

$-$

Joumal of

Control Science

and Engineering
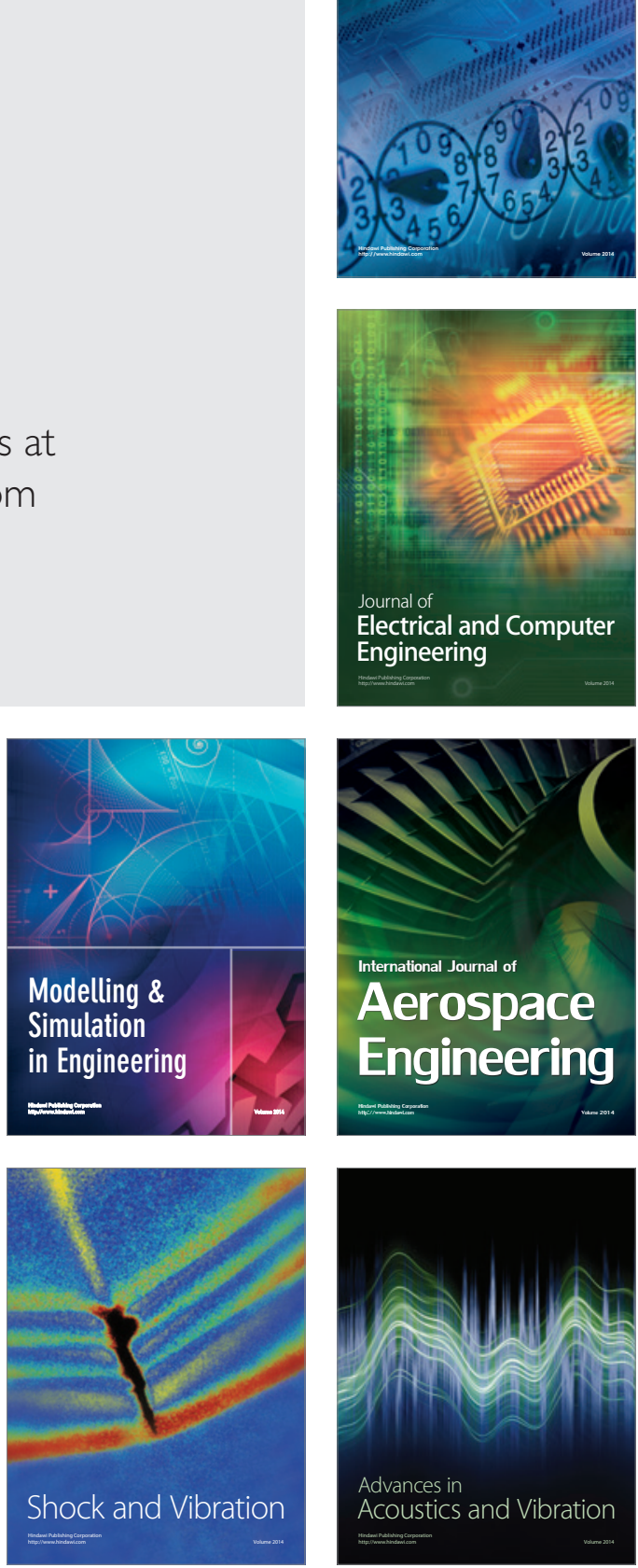